\title{
HIBISCUS EXTRACT MITIGATES SALT INDUCED CAROTID ADVENTITIAL CHANGES IN RATS
}

Fidel 0 Gwala, Beda O Olabu, Anne N Pulei, Julius A. Ogeng'o Correspondence to Fidel O Gwala, Department of Human Anatomy University of Nairobi P.O. BOX $30197-00100$.

\begin{abstract}
The tunica adventitia is an active vascular compartment that actively participates in modulation of vascular structure, function and pathophysiology. Adventitial thickness has recently been accepted as a surrogate marker of atherosclerosis. The effects of salt and chemicals that ameliorate those effects are important in understanding vascular structure, function and pathology. There are few studies on hibiscus and high salt induced vascular pathology. This study, therefore, investigated the effects of hibiscus on salt induced vascular changes on rat carotid artery. The experimental animals were divided into 3 groups of 8 animals each - (i) controls; (ii) high salt diet alone and (iii) high salt + hibiscus extract for a period of eight weeks. At ages 2, 5 and 8weeks $2-3$ animals were sacrificed for study. They were anaesthetized with ether and perfused with formal saline. Specimens were then obtained from the middle of common carotid artery, fixed in 5\% formaldehyde solution, processed routinely for paraffin embedding and 5-micron thick sections stained with Hematoxylin / Eosin and also with Mason's Trichome/ Aniline blue. Adventitial thickness and volumetric densities of collagen were measured using morphometric techniques. High salt consumption induced statistically significant increase in adventitial thickness from $297.45 \mu \mathrm{m}$ at week 2 to $659.4 \mu \mathrm{m}$ in week 8 . In hibiscus fed rats, this increase progressively reduced to $482.55 \mu \mathrm{m}$ in week 8 . Volumetric density of collagen was $57 \%$ in high salt fed rats but reduced to $45.66 \%$ in hibiscus fed rats $(p<0.001)$. The increase in tunica adventitial thickness and collagen density which is induced by high salt can be mitigated by hibiscus extract. This implies that hibiscus has potential to restore salt induced vascular injury. Further studies are recommended to refine the extract.

Keywords: adventitial thickness, high salt, hibiscus, collagen, density
\end{abstract}

\section{INTRODUCTION}

Tunica adventitia is an active vascular compartment which participates in vascular homeostasis and pathophysiology (Ogeng'o et al., 2017). Adventitial thickness is now an accepted marker of vascular pathology (Skilton, 2009; 2011; 2012). Identification of substances that ameliorate injury induced increase in adventitial thickness is important in understanding, vascular structure, function, pathophysiology and mitigating vascular disease. Studies reveal that in rats fed on high salt diets, there is arterial wall stiffening attributable to increased collagen deposition (Safar et al., 2000). Further, a high salt diet has been reported to result in adventitial inflammation as a result of activation of pro inflammatory monocytes and macrophages which produce cytokines that inhibit collagen degradation and promote collagen deposition in the tunica adventitia (Sullivan, 2009; Kanbay et al., 2011). Reduced collagen turnover in turn results in adventitial thickening which has been correlated with increased risk of developing atherosclerosis and other cardiovascular diseases [CVDs] [Skilton et al., 2009]. Hibiscus sabdariffa extract (HSE) is commonly used as a traditional remedy that provides an effectively manageable dietimposed treatment that is low on cost and easily available (Seujange et al., 2013; Rawat et al., 2016). It is known to confer cardioprotective effects, partly through its 
antihypertensive actions (Onyenekwe et al., 1999; Sireeratawong et al., 2013; Serban et al., 2015). Consequently, it is important to understand further, the mechanisms of this cardioprotection. The common carotid artery
(CCA) is one of the most commonly afflicted arteries. This study therefore examined the effects of HSE on salt induced adventitial thickness in CCA.

\section{MATERIALS AND METHODS}

This was experimental study involving administration of high salt and hibiscus to examine their effects on the rat common carotid artery. High salt diet was prepared by adding 77 grams of sodium chloride $(\mathrm{NaCl})$ to 723 grams of standard rat chow to make $8 \%$ $\mathrm{NaCl}$ diet (Seujange et al., 2013). Hibiscus Sabdariffa Extract (HSE) was prepared from dry dark red calyces of the plant. 30 gramms of the calyces were immersed in boiling water 30 minutes. The mixture was filtered, and the filtrate allowed to evaporate leaving a dark red powder (Yield: $55 \%$ ) which was then dissolved in distilled water at room temperature. It was administered by gavage. 24 two-month-old experimental animals, that is albino rats (Rattus norvegicus) were obtained from the Department of Biochemistry University of Nairobi. Ethical approval for the study was obtained from the BioSafety, Animal Use and Ethics Committee, Faculty of Veterinary Medicine, University of Nairobi, approval number: FVB/BAUE/2017/130. The rats were randomly selected by simple random sampling and marked 1-24. The numbers were then fed into a random number generating software. From this, 8 random numbers were obtained for each of the 3 groups $(A-C)$. Group $A$ was fed on a diet containing $8 \%$ sodium chloride, Group B was fed on $8 \%$ sodium chloride and HSE by gavage and Group C (the control group) was fed on standard pellets. Feeding was evaluated by a feed efficiency ratio to determine how much food each rat consumes. Water was provided ad libitum.

The first 2 numbers generated for the control group were euthanized at day zero to determine the baseline histomorphometric variables. Two rats from the 3 groups were euthanized at week 2. Six experimental animals and 2 controls were then perfused at week 5 and week 8 from the start of the experiment (Table 1).

Table 1: Timing for perfusion and harvesting

\begin{tabular}{|l|l|l|l|l|l|}
\hline Group & Baseline (day 0) & Week 2 & Week 5 & Week 8 & Total \\
\hline High salt-fed & & 2 & 3 & 3 & 8 \\
\hline High salt-fed + hse & & 2 & 3 & 3 & 8 \\
\hline Controls & 2 & 2 & 2 & 2 & 8 \\
\hline Total & 2 & 6 & 8 & 8 & 24 \\
\hline
\end{tabular}

After perfusion, the CCAs were harvested by extending the midline body incision up to the neck region and reflecting the skin flaps laterally. The right CCA was identified at its junction with the brachiocephalic trunk and the right subclavian artery and the left was identified branching from the arch of the aorta. The whole length of the artery was harvested on both sides upto just before the bifurcation into internal and external carotid arteries.

The rats' whole common carotid arteries were fixed in $10 \%$ formal saline for at least $24 \mathrm{hrs}$. $1 \mathrm{~mm}$ long samples obtained from the middle of the specimen were dehydrated in increasing grades of alcohol, cleared in cedar wood oil and embedded in paraffin wax. Five-micron thick sections were deparaffinized in xylene, 
rehydrated and stained with Hematoxylin/Eosin and Mason's trichome. The slides were examined with a light microscope.

Photomicrographs of the sections were taken using a high-resolution Canon digital camera (12 megapixels) mounted on a photomicroscope. These photographs were entered into Fiji Image J software (NIH image program) for morphometric and stereological analysis.

Five different $5 \mu \mathrm{m}$ sections were sampled from each animal by simple random sampling. Photomicrographs were taken from each section and examined at a magnification of X400. The adventitial thickness (AT) was measured by tracing four random points on the wall of the CCA over the adventitial zone in a photomicrograph of each section [Figure 1].
The average measure was then calculated from the four points as shown below.

$A T=(A T a+A T b+A T c+A T d) / 4$

Volumetric densities of collagen in the tunica adventitia were estimated based on the Cavalieri principle of point counting (Mandarim-deLacerda, 2003). Five different $5 \mu \mathrm{m}$ sections were sampled from each animal by simple random sampling and 4 fields from each section examined at a magnification of X400. Images from these fields were captured and by the methods described by Gundersen et al. (1988) and Bancroft and Cook (1994), an 80-point grid was superimposed on the digital images in order to analyse the selected areas.Point probes from the grid system facilitated estimation of the volumetric densities for collagen distribution.

Figure 1: Estimation of common carotid wall thickness
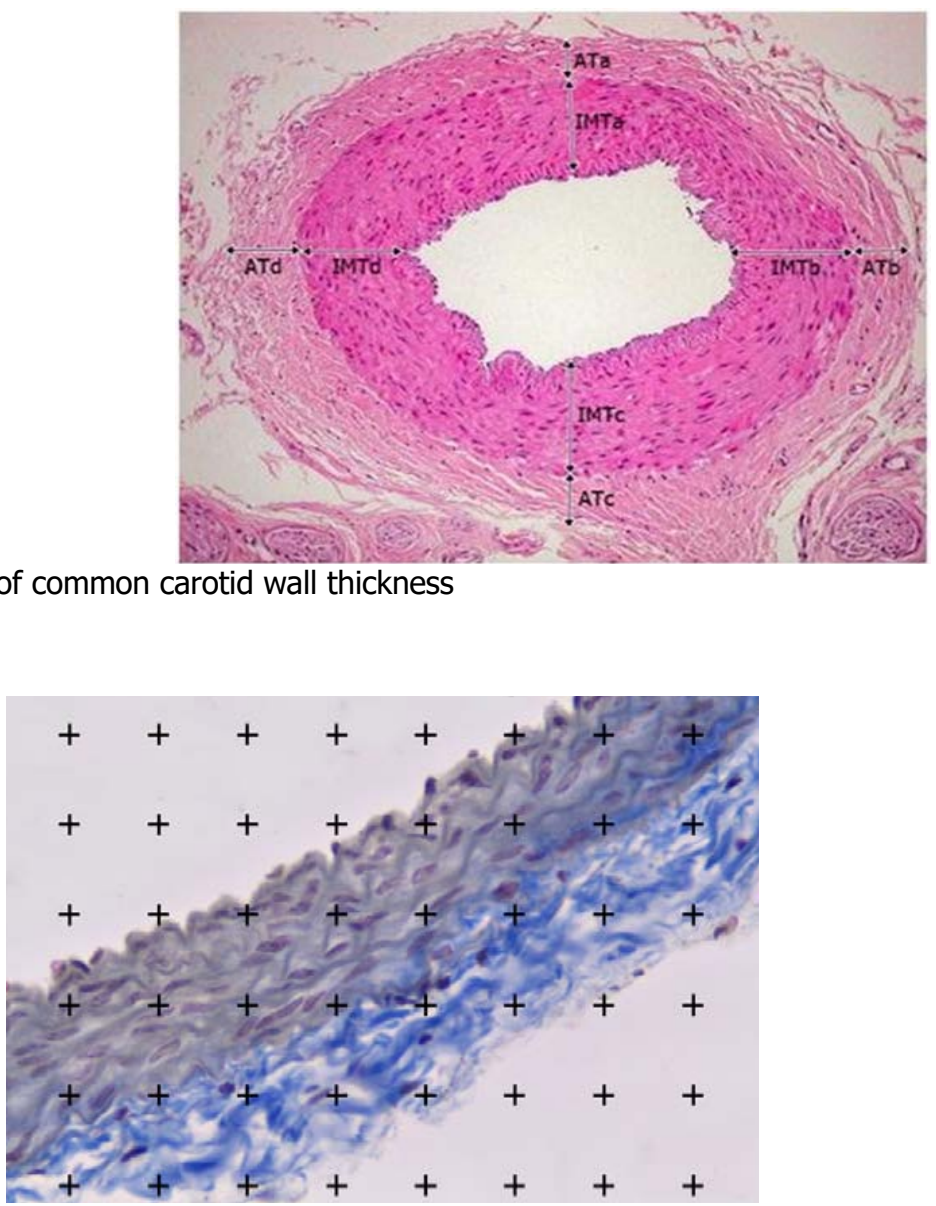

Figure 2: Point counting method to estimate volume densities of connective tissues 
Anatomy Journal of Africa. 2018. Vol 8 (1): $1342-1350$.

The volume densities for collagen were then calculated by the formula $\mathrm{V}_{\mathrm{v}}=\mathrm{P} p / \mathrm{P}$, where $\mathrm{VV}$ is the volume density, $p$ is the adventitial collagen, $\mathrm{P} p$ is the number of test points associated with $p$, and $\mathrm{P} t$ is the total number of points of the test system that touched the tunica adventitial zone. This was done while unaware of the source of the tissues.

Morphometric data on carotid artery thickness was entered into the Statistical Package for Social Sciences (SPSS) software (version 21.0,
Chicago, Illinois) for coding, tabulation and statistical analysis. Measurements are expressed in micrometers. The data are grouped into three; Group A, B and C. Normality of data was determined using histograms and box plots. Kruskal-Wallis $\mathrm{H}$ test was done to compare adventitial wall thickness and collagen fiber density among the groups. Dunn's test was then applied for pair wise comparison. A p-value $\leq 0.05$ was considered statistically significant at a $95 \%$ confidence level.

\section{RESULTS}

The AT was seen to increase in all the groups across the total duration of the study [Figure 3]. There was a statistically significant increase in AT from week 2 [Figure 4A] to week 8 [Figure $4 \mathrm{C}$ ] in the control group. The AT in the control group was $238.19 \mu \mathrm{m}$ at week 2 and $416.82 \mu \mathrm{m}$ at week 8 . A similar statistically significant increase was seen in the experimental groups. In the high salt group, the AT increased from $297.45 \mu \mathrm{m}$ at week 2 to $659.4 \mu \mathrm{m}$ at week 8 [Figure 4B] whereas in the high salt with HSE group it was reduced to $482.55 \mu \mathrm{m}$ by the $8^{\text {th }}$ week. Between the $5^{\text {th }}$ and $8^{\text {th }}$ week the increase in AT was slowed in the high salt with HSE group and control group. Concurrent administration of HSE with high salt loading led to a less pronounced increase in AT [Figure 4D] which was comparable to the normal control. At the $8^{\text {th }}$ week the differences among the three groups were statistically significant.

All the experimental groups showed apparent increase in collagen density throughout the study duration [Figure 5]. Changes in the control group were not statistically significant between the $5^{\text {th }}$ and $8^{\text {th }}$ week [figure $6 \mathrm{~A}$ and $\mathrm{C}$ ]. The High salt group however had the highest collagen density by week 8 of 57\% [Figure 6B] which was a statistically significant increase from the adventitial collagen density in week 2 of the same group $(p<0.001)$. The HSE + High salt group had lower collagen density (45.76\%). Although there was marked increase in the adventitial collagen density [Figure 6D], this was significantly different from the High salt group $(p<0.001)$. Volumetric density of collagen in the tunica adventitia is represented below [Figure 5]. 


\section{CHANGES IN ADVENTITIAL THICKNESS}

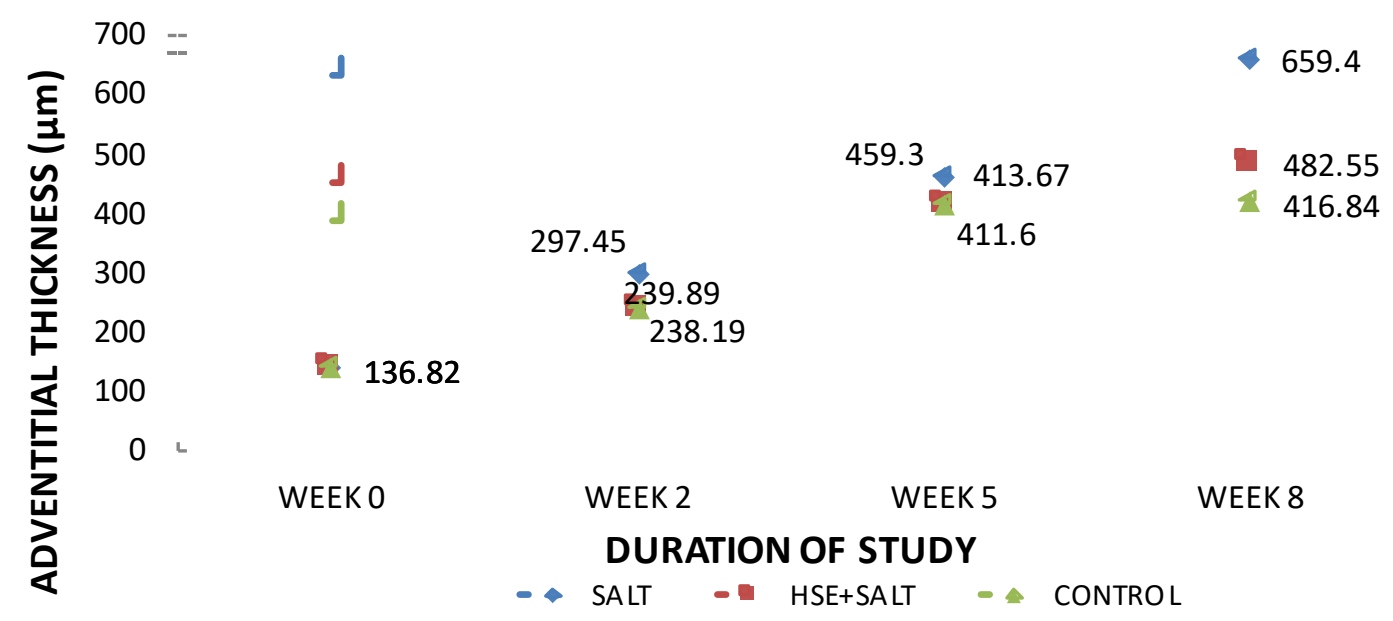

Figure 3: Line graph showing trends in adventitial thickness in control and experimental groups
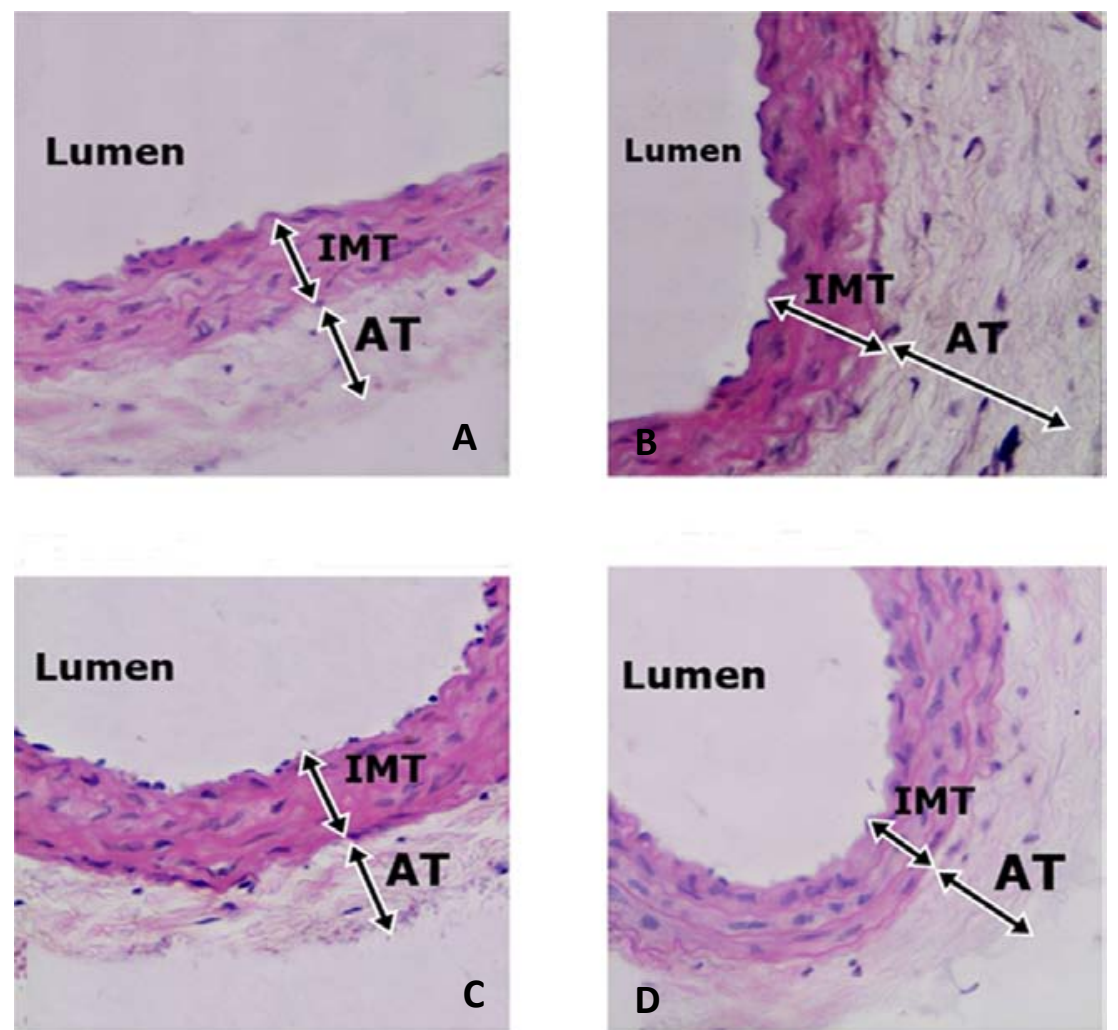

Figure 4A- D: Photomicrographs showing changes in the Adventitial thickness of the common carotid artery with time in control and experimental groups. Hematoxylin/Eosin Stain x 400. AT = Adventitial Thickness; IMT = Intima Media Thickness. A: The control group at week 2 of the study. B: High salt group at week 8 of the study. Notice the prominent adventitial thickness (AT). This represents an increase in AT when compared to figure 4A. C: The control group at week 8 of the study. Notice the adventitial thickness (AT) almost comparable to that of week 2 and before intervention. D: Hibiscus sabdariffa extract (HSE) + high salt group at week 8 of the study. Notice the AT is reduced when compared to the high salt group at week 8 [figure 4B]. 


\section{ChaNGES IN ADVENTITIAL COLLAGEN DENSITY IN CONTROL AND EXPERIMENTAL ANIMALS}
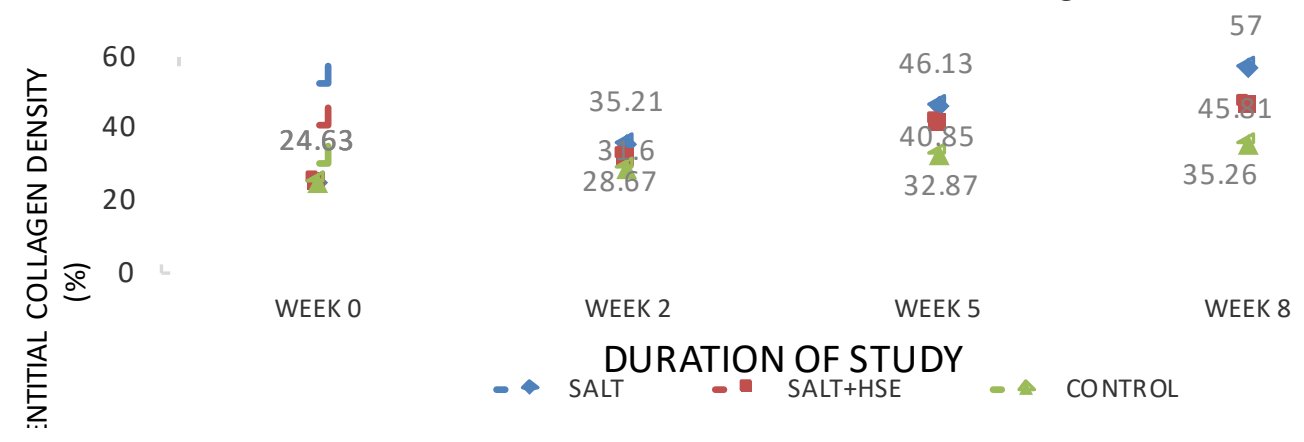

Figure 5: Volumetric density of adventitial collagen in the control and experimental
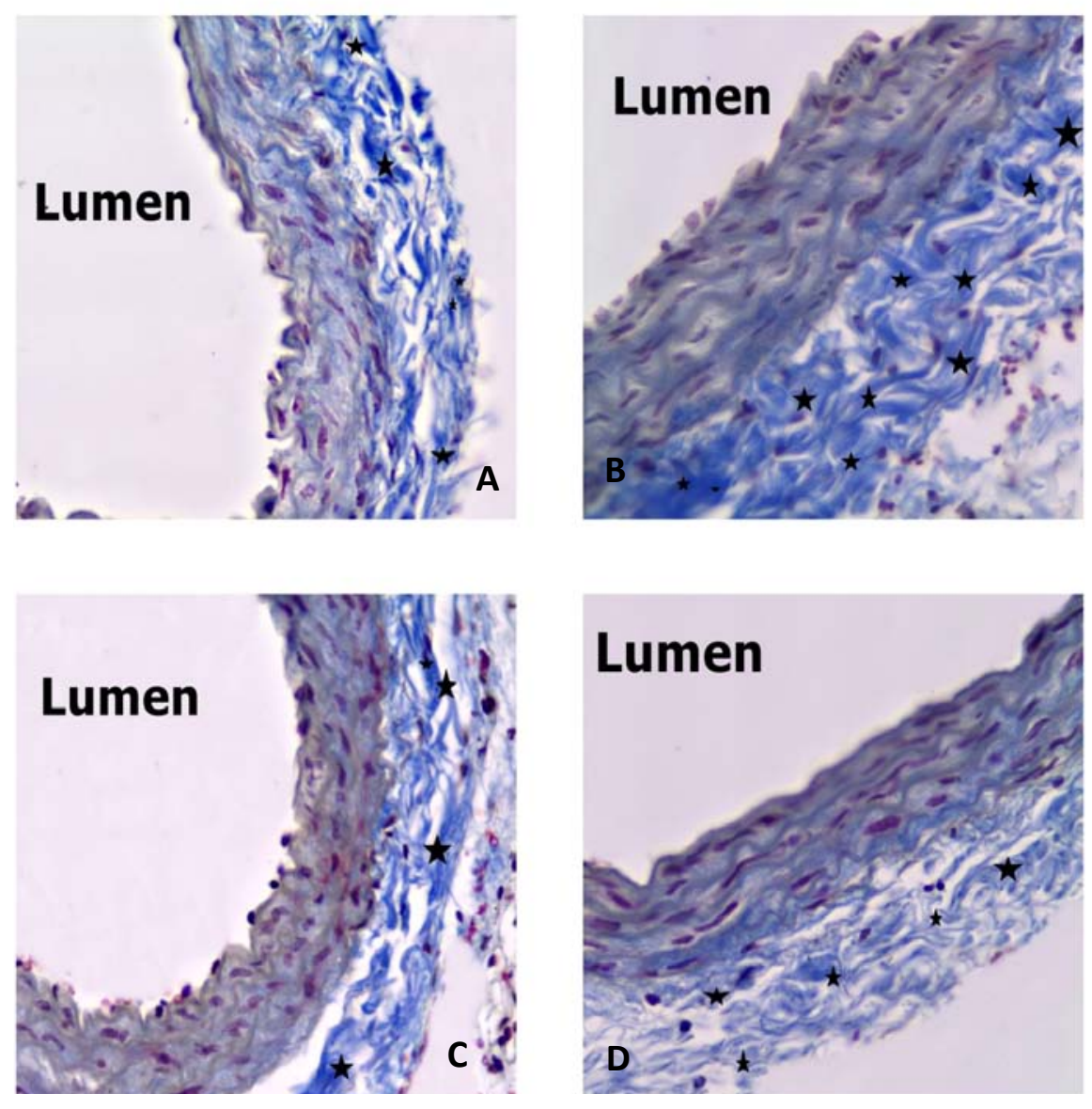

Figure 6A - D: Micrograph showing changes in collagen density in the control and experimental groups. Mason's Trichome/aniline blue stain x400. A: The control group at week 2 of the study. Notice the collagen bundles (asterisks) in the tunica adventitia with numerous spaces in between. B: The high salt group at week 8 of the study. Notice the dense collagen bundles (asterisks) in the extensive tunica adventitia with few spaces in between. The extensive collagen represents a significant increase compared to figure $A$ and $C$. C: The control group at week 8 of the study. Notice the collagen bundles (asterisks) in the tunica adventitia with numerous spaces in between. This is closely comparable to figure A. D: HSE with high salt group at week 8 of the study. Notice the collagen bundles (asterisks) in the tunica adventitia with numerous spaces in between. This represents a significant reduction when compared to figure $B$. 


\section{DISCUSSION}

Observations of the current study reveal that high salt intake increases adventitial thickness (AT) and collagen density. Both effects are attenuated by concomitant ingestion of HSE. Adventitial thickening commonly occurs with aging (Fleenor, 2012) and development of atherosclerosis (Ogeng'o et al., 2014b). The present study demonstrates a statistically significant increase in AT in the high salt fed rats. This is similar to the findings of Saka et al., (2016) on the aorta of adult Wistar rats. The AT attributable to invasion of macrophages and other inflammatory cells and release of pro-fibrotic cytokines, transforming growth beta [TGF - $\beta$ ] and Tumor Necrosis Factor a (TNF a) which stimulate adventitial fibroblasts to synthesize and secrete collagen fibres and ECM (Sullivan et al., 2009; Fleenor, 2012; Kanbay et al., 2011; Dai et al., 2016). Further, the TGF- $\beta$ inhibits matrix metaloproteinases (MMPs) responsible for extracellular matrix degradation (Risinger et al., 2010) and collagen fiber degradation (Ferreira-sae et al., 2011) Conceivably, if the pro-inflammatory process

Observations of the current study reveal that high salt intake increases collagen density in the tunica adventitia (TA). This increase may be attributed to salt induced inhibition of MMP mediated collagenolysis (Sanders 2009a; Meng et al., 2015), and upregulation of collagen production (Ferreira - Sae et al., 2011). Further there is recruitment of macrophages into the TA (Kanbay et al., 2011) and their stimulation to produce pro - fibrotic cytokines like TGF - $\beta$ which inhibit collagen degradation and activate adventitial fibroblasts to secrete collagen (Ferreira - Sae et al., 2011; Majesky et al., 2011). The increase in TA collagen density may constitute part of the mechanism for salt induced in arterial stiffness and hypertension (Du Pont et al., 2013; Renna et al., 2013). This implies that reduction of salt intake constitutes an important step in the control of CVD. induces adventitial thickening in atherosclerosis, it may be associated with a high salt diet with onset of atherosclerosis through the same process (Dai et al., 2016).

The HSE reduced the high salt induced adventitial thickening, similar to the effect of garlic extract (Saka et al., 2016). The possible mechanisms may include the extract's stimulation nitric oxide synthase of and its modulation of endothelial TGF- $\beta$, reducing oxidative stress and lowering TGF- $\beta$ production which effectively checks pro-fibrotic activity of the induced cytokines in high salt diet (Sanders, 2009b).

Adventitial thickening together with IMT, provide a more complete picture in the assessment of atherosclerosis (Skilton et al., 2011; Ogeng'o et al., 2014) and has become a target for therapeutic intervention, (Skilton et al., 2012). Accordingly, the current study underpins the potential for use of HSE in mitigating CVD, in the background of high salt intake.

Concomitant ingestion of HSE significantly attenuated the high salt induced increase in TA collagen density. This is consistent with antifibrotic effects of HSE (Seujange et al., 2012) which are probably mediated through its antioxidant effects which upscale production of nitrous oxide (Sanders et al., 2009b) and the inhibition of fibrosis inducing effects of TNF - a and TGF - $\beta$ (Chen et al., 2014; Lan et al., 2013; Meng et al., 2015). This attenuation of salt induced TA fibrosis may provide part of the explanation for the antihypertensive effects of HSE (Serban et al., 2015) and underpin its potential in the prevention of CVD including atherosclerosis.

In conclusion Hibiscus extracts ameliorates high salt induced adventitial thickening. This implies that it has therapeutic potential in management of atherosclerosis. Further studies are recommended. 
Anatomy Journal of Africa. 2018. Vol 8 (1): $1342-1350$.

ACKNOWLEDGEMENT: We are grateful to staff of the Departments of Human Anatomy, Medical Biochemistry and Botany for technical assistance, and to Ms Antonina Odock for typing and editing the manuscript.

\section{REFERENCES}

1. Bancroft JD, Cook HC. 1994. Manual of histological techniques and their diagnostic application. Churchill Livingstone, Edinburgh; $35-67$.

2. Chen HY, Zhong X, Huang XR, Meng XM, You Y, Chung AC, Lan HY. 2014. Micro RNA - 29b inhibits diabetic nephropathy in db/db mice. Molecular Therapy, 22: $842-853$.

3. Dai XW, Wang C, Xu Y, Guan K, Su YX and Chen YM, 2016. Urinary Sodium and Potassium Excretion and Carotid Atherosclerosis in Chinese Men and Women. Nutrients, 8:612.

4. Du Pont JJ, Greaney JL, Wenner MM, Lennon - Edwards SL, Sanders PW, Farquhar WB, Edwards DG. 2013. High dietary sodium intake impairs endothelium - dependent dilation in healthy salt resistant humans. Journal of Hypertension, 31: 530.

5. Ferreira-Sae MC, Cipolli JA, Cornélio ME, Matos-Souza JR, Fernandes MN, Schreiber R, Costa FO, Franchini KG, Rodrigues RC, Gallani MC and Nadruz W, 2011. Sodium intake is associated with carotid artery structure alterations and plasma matrix metalloproteinase- 9 upregulation in hypertensive adults. The Journal of nutrition, 141:877-882.

6. Fleenor BS, 2012.Large elastic artery stiffness with aging: Novel translational mechanisms and interventions. Aging and Disease. 4:76-83.

7. Gundersen HJ, Bagger P, Bendtsen TF, Evans SM, Korbo L, Marcussen N, Moller A, Nielsen K, Nyengaard JR, Pakkenberg B, 1988. The new stereological tools: dissector, fractionator, nuclear and point sampled intercepts and their use in pathological research and diagnosis. Acta Pathologica, Microbiologica et Immunologica Scandinavia; 96:857-881.

8. Lan TH, Huang XQ, Tan HM. 2013. Vascular fibrosis in atherosclerosis. Cardio Path, 22: 401 407.

9. Kanbay M, Chen Y, Solak Y, Sanders PW, 2011. Mechanisms and consequences of salt sensitivity and dietary salt intake. Current Opinion in Nephrology and Hypertension, 20(1):3743

10. Majesky MW, Dong XR, Hoglund VJ, Mahoney WM, Daum G, 2011. The adventitia: a dynamic interface containing resident progenitor cells. Arteriosclerosis, Thrombus and Vascular Biology, 31: $1530-1539$

11. Mandarim de Lacerda CA, 2003. Stereological tools in biomedical research. Anaisda Academia Bras de Cien, 75: 469 - 486.

12. Meng XM, Tang PMK, Li J and LAn HY. 2015. TGF- $\beta / S m a d$ signaling in renal fibrosis. Frontiers in Physiology, 6.

13. Ogeng'o J, Ongeti K, Obimbo M, Olabu B, Mwachaka P, 2014a. Features of atherosclerosis in the tunica adventitia of coronary and carotid arteries in a black Kenyan population. Anatomy Research International. 2014: e456741.

14. Ogeng'o JA, Mwachaka PM and Ongeti KW, 2014b. Non-smooth muscle cells in the tunica media of the aorta. Anatomy Journal of Africa, 3:250-254.

15. Ogeng'o JA, Ominde BS, Ongeti K, Olabu BO, Obimbo M, Mwachaka P. 2017. Reappraisal of the structure of arterial tunica adventitia and its involvement in atherosclerosis. Anat J Afr, 2017; 6: $824-833$.

16. Onyenekwe PC, Ajani EO, Ameh DA and Gamaniel KS, 1999. Antihypertensive effect of roselle (Hibiscus sabdariffa) calyx infusion in spontaneously hypertensive rats and a comparison of its toxicity with that in Wistar rats. Cell Biochemistry and Function, 17:199-206. 
17. Rawat P, Singh P K and Kumar V, 2016. Antihypertensive Medicinal Plants and their Mode of Action. Journal of Herbal Medicine, 6:107-118

18. Renna NF, de las Heras N, Miatello RM. 2013. Pathophysiology of vascular remodeling in hypertension. Int J Hyper, 2013: $85-87$.

19. Risinger GM, Updike DL, Bullen EC, Tomasek JJ and Howard EW, 2010. TGF- $\beta$ suppresses the upregulation of MMP-2 by vascular smooth muscle cells in response to PDGF-BB. American Journal of Physiology-Cell Physiology, 298:C191-C201.

20. Safar ME, Thiulliez $\mathrm{CH}$, Richard V and Benetos A, 2000. Pressure-independent contribution of sodium to large artery structure and function in hypertension. Cardivascular research, 46:269276

21. Saka OS, Komolafe AO, Ogunlade O, Olayode AA and Akinjisola AA, 2016. Aqueous extract of garlic (Allium sativum) administration alleviates high salt diet- induced changes in the aorta of adult Wistar rats: a morphological and morphometric study. International Journal of Experimental and Clinical Anatomy, 10:7-15

22. Sanders PW, 2009a. Dietary salt intake, salt sensitivity, and cardiovascular health. Hypertension, 53:442-445A

23. Sanders PW. 2009b. Vascular consequences of dietary salt intake. American Journal of Physiology - Renal Physiology, 297: F237 - F243B.

24. Serban C, Sahebkar A, Ursoniu S, Andrica F and Banach M, 2015. Effect of sour tea (Hibiscus sabdariffa L.) on arterial hypertension: a systematic review and meta-analysis of randomized controlled trials. Journal of hypertension, 33:1119-1127.

25. Seujange $Y$, Leelahavanichkul A, Yisarakun W, KhawsukW, Meepool A, Phamonleatmongkol $P$, Saechau W, Onlamul W, Tantiwarattanatikul P, Oonsook W and Eiam-Ong S, 2013. Hibiscus sabdariffa Linnaeus aqueous extracts attenuate the progression of renal injury in $5 / 6$ nephrectomy rats. Renal failure, 35:118-125.

26. Sireeratawong $S$, Itharat $A$, Khonsung $P$, Lertprasertsuke $N$ and Jaijoy $K, 2013$. Toxicity studies of the water extract from the calyces of Hibiscus sabdariffa L. in rats. African Journal of Traditional, Complementary and Alternative Medicines, 10:122-127.

27. Skilton MR, Boussel L, Bonnet F, Bernard S, Douek PC, Moulin P, Serusclat A, 2011. Carotid intima-media and adventitial thickening: Comparison of new and established ultrasound and magnetic resonance imaging techniques. Atherosclerosis, 215:405-410.

28. Skilton MR, Serusclat A, Sethu AHAU, 2009. Non-Invasive measurement of carotid extramedial thickness: association with cardiovascular risk factors and intima - media thickness. Journal of American College of Cardiology: Cardiovascular Imaging, 2: 176 - 182.

29. Skilton MR, Sullivan TR, Ayer JG, Harmer JA, Toelle BG, Webb K, Marks GB, Celermajer DS, 2012. Carotid extramedial thickness in childhood: early life effects on the arterial adventitia. Atherosclerosis, 222: $478-482$.

30. Sullivan DE, Ferris M, Nguyen $H$, Abboud E and Brody AR, 2009. TNF-a induces TGF- $\beta 1$ expression in lung fibroblasts at the transcriptional level via AP-1 activation. Journal of cellular and molecular medicine, 13:1866-1876. 